\title{
OVARIAN MASSES IN WOMEN: A RETROSPECTIVE ANALYSIS IN TERTIARY CARE CENTER
}

\author{
Uzma Urooj, Sadaf Zohra, Rabiya Akbar, Asifa Siraj, Sumaira Khan, Fatima Amin \\ Pak Emirates Military Hospital/National University of Medical Sciences (NUMS) Rawalpindi Pakistan
}

\begin{abstract}
Objective: To describe the presenting signs and symptoms, clinic-pathological findings of ovarian masses and to establish diagnostic value of clinical examination, ultrasonography and its correlation with histopathological diagnosis.

Study Design: Cross-sectional study.

Place and Duration of Study: Combined Military Hospital, Rawalpindi Jun 2017 May 2018.

Methodology: Women who underwent surgery for ovarian masses were included. Data was collected from hospital records including; age, presenting symptoms, duration of symptoms, changes in menstrual cycle, and the results of the physical examination. The preliminary diagnoses as well as the final diagnosis were noted.

Results: A total of 83 patients with ovarian masses, who underwent surgery over the period of a year, were included. The most common symptom was abdominal pain in 56 (67.5\%) followed by abdominal distention $9(10.8 \%)$, dysmenorrhea 8 (9.6\%). When both clinical and sonological diagnosis were combined, the overall sensitivity, specificity, positive and negative predictive value for diagnosis and discriminating benign and malignant ovarian neoplasms were $87.5 \%, 96.7 \%, 70 \%$, and $98.88 \%$, respectively.

Conclusion: In this study most, common symptom was abdominal pain both in benign and malignant ovarian masses. Whereas, abdominal distention was more common in malignant masses. Preoperative diagnostic approach should always include careful history taking, physical examination, imaging and evaluation of tumor markers. Early detection, thorough treatment and regular follow-up are the need of time to reduce the morbidity and mortality.
\end{abstract}

Keywords: Ovarian masses, Ovarian tumors, Pelvic pain, Signs and symptoms, Tumor markers.

This is an Open Access article distributed under the terms of the Creative Commons Attribution License (http://creativecommons.org/licenses/by/4.0), which permits unrestricted use, distribution, and reproduction in any medium, provided the original work is properly cited.

\section{INTRODUCTION}

Ovarian cancer is one of the most important gynecologic cancers. About $20 \%$ of women develop an andexal mass at some time in their lives ${ }^{1}$. The rates are generally lower for Asian and African countries which shows the geographical differences in cancer incidence and mortality ${ }^{2}$. Most of the lesions are benign functional cyst or neoplasm in children and adolescent ${ }^{3}$. The incidence of ovarian malignancy in premenarchal girls is $10-12 \%$, although difficult to establish because most series include prepubertal as well as post-pubertal girls ${ }^{4}$. Ovarian tumor is the seventh leading cause of cancer death among women worldwide, and in Pakistan, it is up to $8.7 \%$ of cancers. Amongst numerous types of ovarian tumors; both benign and malignant, about $80 \%$ are benign in young women aged between 20 and 45 years. The malignant tumors are more common in older women aged between 40-65 years. Ovarian cancer is the 4 th most common malignancy in Pakistani women. Ovarian tumors present a special diagnostic challenge, especially in children and adolescents, because their clinical signs and symptoms are usually non-specific as well as benign neoplasms greatly outnumber malignant. Determination of a deg-

Correspondence: Dr Uzma Urooj, Flat G, Block 4, Range Road, Opposite CMH Rawalpindi Pakistan

Received: 14 Feb 2020; revised received: 12 Apr 2020; accepted: 17 Apr 2020 ree of suspicion for ovarian malignancy is critical and a multi-modal approach (i.e. clinical examination, imaging and serum assays) is necessary to detect malignant masses at an early stage. After a thorough, diagnostic work-up it is easier to decide the appropriate management for the patient. Surgical emergencies of gynecological origin occur in women of reproductive age group and sometimes in adolescents. Early diagnosis and intervention are essential to conserve the function of ovaries and to prevent further complications. An increased rate of ovary sparing procedures are done but it is pertinent to pointout that too many oophorectomies are still performed. They can cause chronic lower abdominal pain or acute pain due to rupture of ovarian cyst, torsion of adnexa with or without a tumor, hemorrhage into a cyst, acute pelvic infections and non-gynecological causes as well. Malignancy and endometriomas has to be kept in mind in peri-menopausal women. Conservation of ovaries should be considered in young women and only cystectomy should be done, whereas hysterectomy with removal of the tubes and ovaries can be considered in perimenopausal and postmenopausal women ${ }^{5}$.

This article presents retrospective information collected on 83 patients with ovarian masses in terms of age, presenting symptoms, tumor markers and clinicopathological. This study was done to describe 
the presenting signs and symptoms, clinic-pathological findings of ovarian masses and to establish diagnostic value of clinical examination, ultrasonography, its correlation with histopathological diagnosis in our clinical context.

\section{METHODOLOGY}

This was a cross sectional study which included 83 women, who underwent ovarian surgery for ovarian masses at Combined Military Hospital, Rawalpindi, from June 2017 to May 2018. Sample size was calculated by using open Epi calculator. The prevalence of ovarian masses is 9.2/100,000 in Asian women $^{6}$. After approved by the Institutional Review Board ER/81, written informed consent was taken before collecting data. Purposive sampling was done. Eligibility criteria included histologic documentation of ovarian mass and complete data entry in hospital. The following data were collected; age, presenting symptoms, duration of symptoms, changes in menstrual cycle, and the results of the physical examination. The preliminary diagnoses as well as the final diagnosis (pathologic, tumor markers, radiologic, surgical), were obtained. Radiologic, intraoperative and histopathological results werenoted. Data was collected and analyzed using SPSS-20. Frequency, percentages were calculated, $p$-values calculated by chi-square test and t-test where a $p$-value $\leq 0.05$ was considered significant.

\section{RESULTS}

We operated on Eighty-three patients with ovarian masses over the period of a year. The mean age of patients was $32.5 \pm 3.4$ to 3.9 years. Out of 83 women presenting to gynecology department $68(81.9 \%)$ were married and $15(18 \%)$ were unmarried. The menopausal status is shown in table-I.

The frequency of symptoms was abdominal pain $56(67.5 \%)$ followed by abdominal distention 9 (10.8\%), dysmenorrhea $8(9.6 \%)$, postmenopausal spotting 5 $(6 \%)$ pressure symptoms $2(2.4 \%)$ and vaginal discharge in $1(1.2 \%)$ patient. It was interesting to note that abdominal pain was more frequent in patients with benign tumors as compared to malignant tumors. Whereas, abdominal distention was more common in elderly patients with malignant tumors. The median duration of symptoms were 3 weeks, prior to diagnosis. The symptoms were not related to size of the tumor, patients with endometriotic cysts and benign tumors had more abdominal. The largest size tumor was $16 \mathrm{~cm} \times 10 \mathrm{~cm} \times 9 \mathrm{~cm}$ which was present in an unmarried girl.
On physical examination, $55(66.26 \%)$ of women had abdominal tenderness, and $20(24.25 \%)$ had a mass palpated. On pelvic examination, pelvic mass was palpated in $2(11.6 \%)$. Out of 30 patients who had rectal examination, mass was palpated in $2(6.6 \%)$ patients, one of which was not palpable on abdominal examination. Vaginal discharge and cervical motion tenderness were noted in 4 (4.8\%), only 1 patient had both vaginal discharge and cervical motion tenderness. Interestingly, there was no relationship found in signs and type or size of tumor. Neither these signs were related to menopausal status or age of the patient.

Table-I: Menopausal status.

\begin{tabular}{|c|c|c|c|}
\hline \multicolumn{2}{|c|}{ Menopausal Status } & \multicolumn{2}{|c|}{ n (\%) } \\
\hline \multicolumn{2}{|c|}{ Premenopausal } & \multicolumn{2}{|c|}{$56(67.5 \%)$} \\
\hline \multicolumn{2}{|c|}{ Postmenopausal } & \multicolumn{2}{|c|}{$27(32.5 \%)$} \\
\hline \multicolumn{4}{|c|}{ Table-II: Histopathological findings. } \\
\hline \multicolumn{2}{|c|}{ Histopathology } & \multicolumn{2}{|c|}{ No. of Cases (\%) } \\
\hline \multicolumn{2}{|c|}{ Clear cell Carcinoma } & \multicolumn{2}{|c|}{$1(1.2 \%)$} \\
\hline \multicolumn{2}{|c|}{ Corpus luteal cyst } & \multicolumn{2}{|c|}{$4(4.8 \%)$} \\
\hline \multicolumn{2}{|c|}{ Dermoid } & \multicolumn{2}{|c|}{$3(3.6 \%)$} \\
\hline \multicolumn{2}{|c|}{ Dermoid cyst } & \multicolumn{2}{|c|}{$2(2.4 \%)$} \\
\hline \multicolumn{2}{|c|}{ Ectopic pregnancy } & \multicolumn{2}{|c|}{$1(1.2 \%)$} \\
\hline \multicolumn{2}{|c|}{ Endometriosis } & \multicolumn{2}{|c|}{$15(18 \%)$} \\
\hline \multicolumn{2}{|c|}{ Granulosa cell tumor } & \multicolumn{2}{|c|}{$5(6 \%)$} \\
\hline \multicolumn{2}{|c|}{ Hemorrhagic cyst } & \multicolumn{2}{|c|}{$8(9.6 \%)$} \\
\hline \multicolumn{2}{|c|}{ Mesenteric cyst } & \multicolumn{2}{|c|}{$1(1.2 \%)$} \\
\hline \multicolumn{2}{|c|}{ Serous cyst adenoma } & \multicolumn{2}{|c|}{$15(18 \%)$} \\
\hline \multicolumn{2}{|c|}{ Mucinous cyst adenoma } & \multicolumn{2}{|c|}{$5(6 \%)$} \\
\hline \multicolumn{2}{|c|}{ Metastasis } & \multicolumn{2}{|c|}{$4(4.8 \%)$} \\
\hline \multicolumn{2}{|c|}{ Mucinous cyst adenocarcinoma } & $3\left(3.6^{\circ}\right.$ & \\
\hline Recurrence & & $4\left(4.8^{\circ}\right)$ & \\
\hline Serous cyst a & ocarcinoma & $4(4.8 \%$ & \\
\hline Serous papill & carcinoma & $7\left(8.4^{\circ}\right.$ & \\
\hline Struma ovari & & $1(1.2 \%$ & \\
\hline $\begin{array}{l}\text { Table-III: M } \\
\text { diagnosis. }\end{array}$ & nancy suspici & and histopa & blogical \\
\hline & Histopatholo & al Diagnosis & \\
\hline Diagnosis & $\begin{array}{c}\text { Malignancy } \\
\text { Present } \\
\end{array}$ & $\begin{array}{c}\text { Malignancy } \\
\text { Absent } \\
\end{array}$ & $\begin{array}{c}p- \\
\text { value }\end{array}$ \\
\hline $\begin{array}{l}\text { Malignancy } \\
\text { Present }\end{array}$ & $12(14.4 \%)$ & $7(8.4 \%)$ & 020 \\
\hline $\begin{array}{l}\text { Malignancy } \\
\text { Absent }\end{array}$ & $2(2.4 \%)$ & $62(74.7 \%)$ & $0.0 \angle$ \\
\hline
\end{tabular}

There was correlation in radiological findings and physical examination in locations of the masses in $39(46.9 \%)$ patients, no correction was found $2(2.4 \%)$ patients, and correlation could not be determined in 2 (2.4\%) patients. Ultrasound and/or CT description of these masses revealed that $5(6 \%)$ were at least $6 \mathrm{~cm}$ in largest diameter, $4(4.8 \%)$ were described as large, and 
in $6(7.22 \%)$, no size was recorded, complex cyst with multiple septation were in $54(65.06 \%)$.

Radiologic investigation included abdominal ultrasound in 39 (46.9\%), CT in 19 (22.8\%), barium enema in $3(3.61 \%)$, and intravenous pyelogram in $2(2.4 \%)$. Around $94 \%$ of the ultrasounds and every CT scan showed a mass. The size of the masses was not mentioned in 6 (7.22\%). Rest of the ovarian masses, 9 (10.8\%) were less than $5 \mathrm{~cm}$. Ovarian masses were unilateral in $65(78.3 \%)$ patients and bilateral in $18(21.6 \%)$ patients. Bilateral masses were more common in patient with endometriosis and malignant tumors. The histopathological findings were as shown in table-II.

Malignancy was present in $23(27.2 \%)$ women. Twenty one $(77.7 \%)$ postmenopausal women hadmalignancy. CA-125 was >35 in $66(79.5 \%)$ of patients with malignant tumors and in $17(20 \%)$ patients with benign tumors, whereas in all benign lesions the level was within normal limits.

It was also found that malignancy was more common in postmenopausal women as compared to premenopausal women $p=0.02$ as calculated by applying chi square test. Moreover, pain was more common presenting symptom in premenopausal women as compared to postmenopausal women $p=0.03$.

\section{DISCUSSION}

Ovarian cancer carries the worst prognosis among all gynecological cancers mainly due to the lack of effective screening methods for early detection of the disease $^{7}$. The evaluation of pelvic masses assumes importance due to the fear and anxiety driven by the potential of missing a malignancy. Present study focused on the clinicopathological spectrum of ovarian masses. Patients with ovarian masses often have nonspecific presenting complaints which varied and are often non-specific, making the correct diagnosis more challenging preoperatively. Abdominal pain was one of the most frequent initial symptoms in our study. Menstrual abnormalities and dysmenorrhea were the complaints in patients with clinical diagnoses of endometriotic cysts. Previous study by Sharadha et al, showed that abdominal pain was present in $66 \%$, menstrual symptoms in $30.8 \%$ patients. The mass should be characterized in terms of size, contour, consistency, mobility and tenderness. Hard, irregular masses with restricted mobility increase the clinical suspicion of malignancy. As physical examination is not a reliable diagnostic tool as it has sensitivity of $51 \%$ USG has more pertinent role in initial diagnosis according to Shobha et $a l^{8}$. USG has many advantages being easily available and relatively inexpensive but a lot depends upon operator's experience ${ }^{9}$. One of the earlier studies showed that USG had a sensitivity of $95.5 \%$ and specificity of $61.4 \%{ }^{10}$.

There is no clear definition of size of ovarian masses in medical literature, which can become symptomatic. Same was seen in our study. Torsion or hemorrhage may account for some of the symptoms in smaller cysts, but other causes should be ruled out in these cases ${ }^{11}$. This retrospective analysis concurred the fact that size of tumor was not related to the presenting symptoms. The patient with largest tumor size in fact presented with abdominal distention rather than abdominal pain which was most frequent symptom. Same was seen in previous studies done by Chen et al ${ }^{11}$.

This study suggested that, ovarian functional cysts and benign neoplasms were the most common ovarian masses during perimenopause and adolescent. Templeman and colleagues found that simple nonneoplastic ovarian cysts occurred in $57.9 \%$ of girls and young women $<21$ years of age who were operated on because of non-inflammatory ovarian masses. Similar to our study which mainly consisted of cystectomy or simple excision of the ovarian lesion. In postmenopausal women $>77.7 \%$ were malignant masses which were treated surgically. Our study concluded that the surgical management depends on the preoperative workup, which should always include careful history taking and physical examination, pelvic sonography and serum tumor markers ${ }^{12}$, which is in concurrence to study done by Shahnaz et al. Proper preoperative diagnostic work-up is essential for adequate treatment ${ }^{13,14}$. In this study majority of malignant tumors were in postmenopausal women ${ }^{15}$. Similar findings were seen in another study showing increased incidence of malignancy with increasing age ${ }^{16}$.

Tumor markers specifically CA-125 was raised in all of malignant masses, while rest of the tumor markers were not always associated with malignant masses unlike another study showed that high CA125 levels were responsible for all the false positive diagnosis occurring with risk management model ${ }^{17}$. CA125 is not a tumor-specific antigen; it is also elevated in approximately $1 \%$ of healthy control subjects as shown in previous studies. It is difficult to identify the organ of origin of pelvic masses as there are various common and vague symptoms ${ }^{6}$. Women who have persistent abdominal/pelvic pain, abdominal distention, urinary frequency, bloating or constitutional symptoms need detail evaluation ${ }^{18}$. 


\section{CONCLUSION}

In this study most, common symptom was abdominal pain both in benign and malignant ovarian masses. Whereas, abdominal distention was more common in malignant masses. Preoperative diagnostic approach should always include careful history taking, physical examination, imaging and evaluation of tumor markers. Early detection, thorough treatment and regular follow-up are the need of time to reduce the morbidity and mortality.

\section{CONFLICT OF INTEREST}

This study has no conflict of interest to be declared by any author.

\section{REFERENCES}

1. Radhamani S, Akhila MV. Evaluation of adnexal masses-correlation of clinical, sonological and histopathological findings in adnexal masses. Int J Sci Stud 2017; 4(11): 88-92.

2. Malik IA. A prospective study of clinico-pathological features of epithelial ovarian cancer in Pakistan. J Pak Med Assoc 2002; 52(4): 155-58.

3. Brown MF, Hebra A, Mc Geehin K, Ross III AJ. Ovarian masses in children: a review of 91 cases of malignant and benign masses. J Pediatr Surg 1993; 28(7): 930-32.

4. Diamond MP, Baxter JW, Peerman JCG, Burnett LS. Occurrence of ovarian malignancy in childhood and adolescence: a community-wide evaluation. Obstet Gynecol 1988; 71(6 Pt-1): 858-60.

5. Tripathi P, Singh D, Bagul M. Ultrasonography study of gynecological pelvic masses. Int Res J Clin Med 2016; 1(4): 1-6.

6. Singhal RP, Setia PS, Kaur KP, Mohan V, Bansal P. Role of ultrasound as an imaging modality in neoplastic ovarian masses in a tertiary care hospital. J Evol Med Dent Sci 2017; 6(94): 6858-62.
7. Sharadha SO, Sridevi TA, Renukadevi TK, Gowri R, Binayak D, Indra V. Ovarian masses: changing clinico histopathological trends. J Obstet Gynecol Ind 2015; 65(1): 34-38.

8. Pillai SS. Clinicopathological spectrum of gynecological pelvic masses: a cross-sectional study. Int J Reprod Contracept Obs Gynecol 2017; 29(6): 1915-19.

9. Khushpreet K, Rama G, Arvinder K, Sangeeta A, Vishavveer K. A retrospective clinicopathological study of ovarian tumours. Int J Med Sci Clin Invent 2017; 4(10): 23-29.

10. Deligeoroglou E, Eleftheriades M, Shiadoes V, Botsis D, Hasiakos D. Ovarian masses during adolescence: clinical, ultrasonographic and pathologic findings, serum tumor markers and endocrinological profile. Gynecol Endocrinol 2004; 19(1): 1-9.

11. Chen Y, Wu P, Lang J, Ge WJ, Hartge P, Brinton LA. Risk factors for epithelial ovarian cancer in Beijing, China. Int J Epidemiol 1992; 21(1): 23-29.

12. Kouser S, Yunus S, Mushtaq N. Frequency and presentation of adnexal masses. Pak J Med Heal Sci 2016; 10(1): 19-21.

13. Rosenberg L, Palmer JR, Zauber AG, Warshauer ME, Lewis Jr JL, Strom BL, et al. A case-control study of oral contraceptive use and invasive epithelial ovarian cancer. Am J Epidemiol 1994; 139(7): 654-61.

14. Bray F, Loos AH, Tognazzo S, La Vecchia C. Ovarian cancer in Europe: cross-sectional trends in incidence and mortality in 28 countries, 1953-2000. Int J cancer 2005; 113(6): 977-90.

15. Rauh-Hain JA, Melamed A, Buskwofie A. Adnexal mass in the postmenopausal patient. Clin Obstet Gynecol 2015; 58(1): 53-65.

16. Bennett JA, Oliva E. Pathology of the adnexal mass. Clin Obstet Gynecol 2015; 58(1): 3-27.

17. Aslam N, Tailor A, Lawton F, Carr J, Savvas M, Jurkovic D. Prospective evaluation of three different models for the pre-operative diagnosis of ovarian cancer. BJOG An Int J Obstet Gynaecol 2000; 107(11): 1347-53.

18. Walker M, Sobel M. Diagnosing ovarian cancer. C Can Med Assoc J 2018; 190(42): E1259-62. 